See Article page 1766.

\section{Commentary: Non-A non-B aortic dissection: Not a nonaggressive subtype of distal aortic dissection}

\author{
Leonard N. Girardi, MD
}

The term "non-A non-B" aortic dissection was first put forth in 1994. ${ }^{1}$ In that Journal article, 16 patients with intimal tears "originating close to the left subclavian artery with either proximal or distal extension" were classified as non-A non-B and treated successfully with both conservative management $(5 / 16,0 \%$ mortality) and open surgery (11/16, 9\% operative mortality). Pasic and colleagues ${ }^{2}$ narrowed the definition of non-A non-B dissection to include only those with isolated arch involvement without proximal or distal extension, similar to the "group B" definition given to isolated arch dissections nearly a quarter of a century earlier by Dubost and colleagues. ${ }^{3}$ Since those original descriptions, however, multiple small series reporting the natural history and treatment outcomes for non-A non-B dissection have become obfuscated by the inclusion of isolated arch dissections, arch entry tears with distal extension, and acute type Bs with entry tears beyond the left subclavian artery but with proximal arch extension. These heterogeneous inclusion criteria and the limited follow-up on this subtype from barely $50 \%$ of sites contributing data to large datasets have given cardiovascular surgeons and others caring for these patients the misperception that this is a nonaggressive variant of distal aortic dissection. ${ }^{4}$ However, there is an expanding and contradictory body of evidence illustrating that non-A non-B is not a nonaggressive subtype of distal aortic dissection. Rather, $75 \%$ of those treated conservatively by experienced aortic surgeons may die of an aortic catastrophe within 1 year. ${ }^{5}$

\footnotetext{
From the Department of Cardiothoracic Surgery, Weill Cornell Medical College, New York, NY.

Disclosures: The author reported no conflicts of interest.

The Journal policy requires editors and reviewers to disclose conflicts of interest and to decline handling or reviewing manuscripts for which they may have a conflict of interest. The editors and reviewers of this article have no conflicts of interest.

Received for publication June 24, 2020; revisions received June 24, 2020; accepted for publication June 24, 2020; available ahead of print July 12, 2020.

Address for reprints: Leonard N. Girardi, MD, Department of Cardiothoracic Surgery, Weill Cornell Medical College, 525 East 68th St, M-404, New York, NY 10065 (E-mail: lngirard@med.cornell.edu).

J Thorac Cardiovasc Surg 2022;163:1775-6

$0022-5223 / \$ 36.00$

Copyright (c) 2020 by The American Association for Thoracic Surgery

https://doi.org/10.1016/j.jtcvs.2020.06.101
}

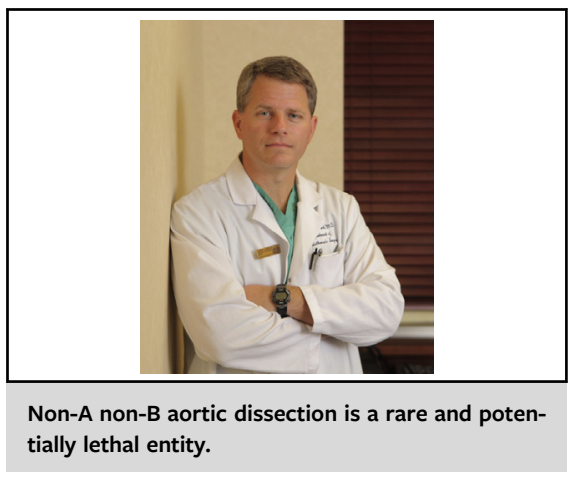

CENTRAL MESSAGE

Non-A non-B aortic dissection is a rare and potentially lethal entity. Primary entry tear exclusion or excision is the key to successful surgical treatment.

With heightened awareness of this potentially lethal entity, a myriad of surgical techniques, both open and endovascular, have emerged to treat non-A non-B dissections. In this issue of the Journal, Wang and colleagues ${ }^{6}$ propose a hybrid technique to treat non-A non-B aortic dissection. Over a 5-year period during which 825 total dissections were admitted to their hospital, they identified a relatively homogeneous cohort of 28 young patients $(3.4 \%$, mean age 53 years) who presented with an entry tear in the arch $(96 \%$ in the posterior arch) and with distal aortic extension. None were managed conservatively. All underwent surgery through a median sternotomy on cardiopulmonary bypass with circulatory arrest under mildly hypothermic conditions using bilateral antegrade cerebral perfusion as an adjunct for cerebral protection. Through a longitudinal arch incision, they closed the entry tear and then deployed a novel composite device consisting of a $10-\mathrm{cm}$, self-expandable stent-graft with a Dacron, stent-free vascular graft at the proximal end. The Dacron graft was sewn around the left subclavian and carotid arteries as an inclusion graft and excluded the previously closed arch entry tear from the systemic circulation. All 28 patients survived to discharge with few perioperative complications. During a short median follow-up time of 15.3 months, they did not identify pseudoaneurysms or retrograde type A dissections and reported significant downstream aortic remodeling. 
Similar to the outcomes reported by others, ${ }^{5,7}$ Wang and colleagues ${ }^{6}$ emphasize primary entry tear exclusion or excision as the likely key to short- and long-term success when treating non-A non-B dissections. Some advocate for open total arch repair with frozen elephant trunk deployment to treat the entry tear and stabilize the distal aorta. Concerns for high operative mortality and spinal cord injury are justified. Others rely primarily on an endovascular strategy to treat non-A non-B dissection. Although this strategy is less invasive and potentially accompanied by lower operative mortality in the emergency setting, approximately 1 of 3 of those surviving the initial procedure require additional interventions. Retrograde type A dissections are particularly troubling with the zone 0 and 1 thoracic endovascular aortic repair needed to address a majority of arch tears. SCI can also complicate these innovative solutions. Irrespective of the preferred treatment algorithm, non-A non-B aortic dissection appears to be a surgical disease. Greater awareness, more experience, and perhaps a different name should contribute to improve outcomes for this rare form of aortic dissection.

\section{References}

1. Von Segesser LK, Killer I, Ziswiler M, Linka A, Ritter M, Jenni R, et al. Dissection of the descending thoracic aorta extending into the ascending aorta. J Thorac Cardiovasc Surg. 1994;108:755-61.

2. Pasic M, Knollman F, Hetzer R. Isolated non-A non-B dissection of the aortic arch. N Engl J Med. 1999;341:1775.

3. Dubost C, Guilmet D, Soyer R. La Chirurgie des Aneurysmes de l'Aorte. Paris: Masson et Cie; 1970. 247-9.

4. Tsai TT, Isselbacher EM, Trimarchi S, Bossone E, Pape L, Januzzi JL, et al. Acute type B aortic dissection: does aortic arch involvement affect management and outcomes? Insights from the International Registry of Acute Aortic Dissection (IRAD). Circulation. 2007;116(11 Suppl):I150-6.

5. Urbanski P, Wagner M. Acute non-A-non-B aortic dissection: surgical or conservative approach? Eur J Cardiothorac Surg. 2016;49:1249-54.

6. Wang W, Piao H, Wang Y, Li B, Zhu Z, Wang T, et al. Early outcomes with a hybrid technique for repair of a non-A non-B aortic dissection. J Thorac Cardiovasc Surg. 2022;163:1766-74.

7. Rylski B, Perez M, Beyersdorf F, Reser D, Kari FA, Siepe M, et al. Acute non-A non-B aortic dissection: incidence, treatment and outcome. Eur J Cardiothorac Surg. 2017;52:1111-7.
See Article page 1766.

\section{Commentary: What's in a name?}

\author{
Anthony L. Estrera, MD
}

"What's in a name? That which we call a rose by any other name would smell as sweet."

Spoken by Juliet in Act 2, Scene 2, of Romeo

and Juliet, by William Shakespeare.

Over the past to 50 years, the classification schema for acute aortic dissection originally developed by DeBakey and the Stanford group have served the medical community well. $^{1,2}$ The Stanford classification (A and B), which was

\footnotetext{
From the Department of Cardiothoracic and Vascular Surgery, McGovern Medical School at The University of Texas Health Science Center at Houston, Houston, Tex. Disclosures: Dr Estrera is a consultant for WL Gore.

The Journal policy requires editors and reviewers to disclose conflicts of interest and to decline handling or reviewing manuscripts for which they may have a conflict of interest. The editors and reviewers of this article have no conflicts of interest.

Received for publication June 29, 2020; revisions received June 29, 2020; accepted for publication June 29, 2020; available ahead of print July 11, 2020.

Address for reprints: Anthony L. Estrera, MD, Department of Cardiothoracic and Vascular Surgery, McGovern Medical School at UTHealth, 6400 Fannin St, Suite 2850, Houston, TX 77030 (E-mail: Anthony.L.Estrera@uth.tmc.edu).

J Thorac Cardiovasc Surg 2022;163:1776-7

0022-5223/\$36.00

Copyright (c) 2020 by The American Association for Thoracic Surgery

https://doi.org/10.1016/j.jtcvs.2020.06.099
}

Check for updates

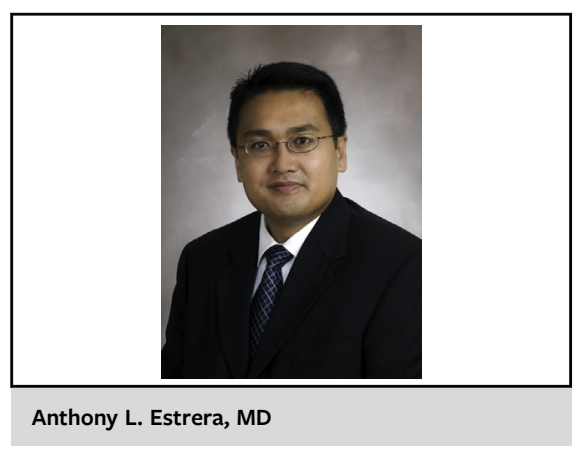

CENTRAL MESSAGE

Although the authors provide a

novel approach to open treat-

ment of acute non-A non-B

aortic dissection, it remains

controversial. The recent STS/

SVS nomenclature may provide

better characterization.

simple, provided practical guidance for both treatment and prognosis. Because of this simplicity, the Stanford classification has been widely adopted by those inside and outside of the cardiovascular surgical community. The DeBakey classification (I, II, IIIa, and IIIb) has also been very 